\title{
Gene transfection of HEK cells on supermacroporous polyacrylamide monoliths: a comparison of transient and stable recombinant protein expression in perfusion culture
}

Article

Accepted Version

Manuscript

Cheeks, M. C., Edwards, A. D., Arnot, C. J. and Slater, N. K.H. (2009) Gene transfection of HEK cells on supermacroporous polyacrylamide monoliths: a comparison of transient and stable recombinant protein expression in perfusion culture. New Biotechnology, 26 (6). pp. 289-299. ISSN 1871-6784 doi: https://doi.org/10.1016/j.nbt.2009.08.006 Available at https://centaur.reading.ac.uk/8004/

It is advisable to refer to the publisher's version if you intend to cite from the work. See Guidance on citing.

Published version at: http://dx.doi.org/10.1016/j.nbt.2009.08.006

To link to this article DOI: http://dx.doi.org/10.1016/j.nbt.2009.08.006

Publisher: Elsevier

All outputs in CentAUR are protected by Intellectual Property Rights law, including copyright law. Copyright and IPR is retained by the creators or other copyright holders. Terms and conditions for use of this material are defined in the End User Agreement. 


\section{www.reading.ac.uk/centaur}

\section{CentAUR}

Central Archive at the University of Reading

Reading's research outputs online 


\title{
Gene Transfection of HEK Cells on Supermacroporous Polyacrylamide Monoliths: A comparison of transient and stable recombinant protein expression in perfusion culture.
}

\author{
Matthew C. Cheeks ${ }^{\mathrm{a}}$, Alexander D. Edwards ${ }^{\mathrm{a}, \mathrm{b}, \mathrm{c}}$, Christopher J. Arnot ${ }^{\mathrm{b}}$, Nigel K. H. Slater ${ }^{\mathrm{a}}$ \\ ${ }^{a}$ Department of Chemical Engineering and Biotechnology, University of Cambridge, New Museums \\ Site, Pembroke Street, Cambridge, CB2 3RA, UK \\ ${ }^{\mathrm{b}}$ Department of Biochemistry, University of Cambridge, Tennis Court Road, Cambridge, UK \\ ${ }^{\mathrm{c}}$ Corresponding Author:
}

Phone: <44> 1223763969

Fax: <44> 1223334796

Email: ade24@cam.ac.uk

\begin{abstract}
:
Transient and continuous recombinant protein expression by HEK cells was evaluated in a perfused monolithic bioreactor. Highly porous synthetic cryogel scaffolds ( $10 \mathrm{ml}$ bed volume) were characterised by scanning electron microscopy and tested as cell substrates. Efficient seeding was achieved (94\% inoculum retained, with $91-95 \%$ viability). Metabolite monitoring indicated continuous cell growth, and endpoint cell density was estimated by genomic DNA quantification to be $5.2 \times 10^{8}, 1.1 \times 10^{9}$ and $3.5 \times 10^{10}$ at day 10,14 and 18 . Culture of stably transfected cells allowed continuous production of the Drosophila cytokine Spätzle by the bioreactor at the same rate as in monolayer culture (total $1.2 \mathrm{mg}$ at $\mathrm{d} 18$ ) and this protein was active. In transient transfection experiments more protein was produced per cell compared with monolayer culture. Confocal microscopy confirmed homogenous GFP expression after transient transfection within the bioreactor. Monolithic bioreactors are thus shown to be a flexible and powerful tool for manufacturing recombinant proteins.
\end{abstract}

Keywords:

Transfection; Monolith; Cryogel; Perfusion; Bioreactor; Continuous culture; Mammalian cell.

\section{Introduction}

Stably transfected cell lines enable high process yields by continuously expressing product at high levels throughout culture. By contrast, the transient transfection approach to product synthesis has been limited mostly to the laboratory scale due to low time-averaged productivity. Nevertheless transient transfection has proven to be a more practical approach for the manufacture of some valuable recombinant biological products, especially viral gene therapy vectors (1), which are commonly toxic and detrimental to the host cell. Developing clones that stably express such 
products has proven to be unsuccessful in many cases, in addition to being complicated, labour intensive, costly and time consuming. Enabling rapid production of large amounts of biological products is desirable for early stage clinical research. For these applications, improved productivity from transiently transfected mammalian cell cultures is required.

Whilst practical and flexible laboratory-scale transient transfection protocols are available, these generally involve low density anchorage-dependent cell cultures grown in monolayer on tissue culture polystyrene plates (TCPS). Most methods are not suited to large scale manufacture due to the cost of materials and equipment, together with the space requirements and the large liquid volumes involved. By contrast, many scalable methods for suspension cell cultures have been reported (2). However, at present the most densely cultured suspension cell lines $\left(\leq 10^{7} \mathrm{cells} \mathrm{ml}^{-1}\right)$ occupy less than $3 \%$ of the available culture volume (3). Because the efficiency of transfection is concentration dependent (4), very large, uneconomical quantities of DNA and chemical transfection reagents become necessary as culture volume increases. Ideally, large numbers of cells should be transfected in small volumes so that minimal quantities of transfection complexes are used whilst still obtaining efficient gene expression.

High cell density cultures of anchorage dependent cells $\left(\approx 10^{8}\right.$ cells.ml support $\left.{ }^{-1}\right)$ on 3 -D surfaces can be achieved using porous microcarrier particles in either fixed or expanded bed culture $(5,6)$. However, in both instances the transport of transfection complexes during culture is limited by intraand inter-particle diffusion $(7,8)$. This reduces cell growth, product recovery and transfection efficiency. Optimising the accessibility of adhered cells can therefore improve culture productivity and lower costs.

Monoliths are a relatively new class of 3-D culture substrate with superior mass transport properties compared to conventional particulate materials (9). They consist of a single block of highly porous polymer to which cells can attach and grow $(10,11)$. Ideally, channels within the polymer are highly interconnected with no dead ends. Axial flow through the monolith enables rapid mass transport to the material surface by convection circumventing the problems associated with inter-particle and intra-particle diffusion.

Continuous product expression from cultured cells grown on monolithic substrates in a perfused fixed bed bioreactor has already been demonstrated $(10,11)$. The current study is focussed on gene transfection of HEK 293 cells cultured within a bioreactor. We hypothesized that improved accessibility of transfection complexes to cells grown within monoliths could improve the efficiency of transient transfection during culture. Therefore the goal of this study was to quantify recombinant protein expression by HEK 293 cells in the stable and transient mode and compare these results with data obtained from conventional 2-dimensional T-flask culture. Spätzle is a cytokine involved in the immune response of drosophila. Spätzle production was studied because the protein is related to human cytokines (being most closely related to nerve growth factor), it is simple to measure activity and thus to confirm folding using a cell-based reporter system, and it contains multiple tags for specific detection and purification (12). This study shows that high productivity is possible with the monolith system, both with stable and transient transfection. With further development the platform can become a flexible, powerful and efficient tool for continuous or transient manufacture of highvalue biological pharmaceuticals.

\section{Materials and Methods:}


The following were purchased from Sigma (Poole, UK): acrylamide, N,N,N',N'tetramethylethylenediamine (TEMED), ammonium persulfate (APS), N,N'-methylenebis (acrylamide), ethylene diamine tetra-acetic acid (EDTA), calcium chloride, sodium dodecylsulphate (SDS), ethanol, phenol, triton X-100, chloroform, tris(hydroxymethyl)aminomethane, proteinase K, bovine serum albumin (BSA), trypan blue dye, purified anti-FLAG clone M2 antibody, HRPconjugated anti-His tag antibody, Sigma FAST o-phenylenediamine dihydrochloride substrate (OPD), and Nunc T-flasks (NY, USA). OptiMEM and DMEM (Dulbecco's Modified Eagles Medium) cell culture media, phosphate-buffered saline (PBS), FoamAway antifoam solution, puromycin, trypsin-EDTA solution, penicillin and streptomycin solution, lipofectamine 2000, Phalloidin, AcTEV protease and fetal calf serum (FCS) were purchased from Invitrogen (Paisley, UK).

\section{Plasmids and cell lines}

Drosophila cytokine Spätzle, engineered with two tags (His-tag for purification, FLAG tag for ELISA detection) plus a TEV cleavage site to determine cytokine activity, was used as a model to study protein production. To make the pcDNA3.1/Spl used for transient expression, the Spätzle EST clone HL01462 (Invitrogen) was modified previously (12) via several rounds of PCR to create the construct N-prodomain-6xHis-TEV-C106-C, containing the pro-domain (Met1-Arg164), a 6xHis tag, a recombinant TEV protease cleavage site and the C-106 domain (Val165-Gly270). A Cterminal FLAG tag was then introduced via PCR using this construct as a template to create a new dual-tagged construct, N-prodomain-6xHis-TEV-C106-FLAG-C. The following primers were used to generate this construct: 5'-ggaattccggatccatgatgacgeccatgtgg-3' and 5'-

tacatagcggccgectacttgtcgtcatcgtcttgtagtccc cagtcttcaacgcgcacttgcagcagg-3'. Following the PCR, the fragment was purified, restricted with BamHI and NotI, then cloned into pcDNA3.1(+) and sequenced. To make $\mathrm{pCEP} / \mathrm{Spl}$ for stable expression, the episomally maintained expression plasmid pCEP (Invitrogen) was used containing the EBV origin of replication and modified to contain a puromycin resistance gene. Spätzle was restricted out of pcDNA3.1/Spl using HindIII and NotI and sub-cloned into the mammalian expression plasmid pCEP-Pu and sequenced. For transient GFP expression pHRVSINctwSVGFP was used (13).

For transient expression of Spätzle, the H6-18 line was used. This line is derived from 293T HEK cells and is routinely used in our laboratory for lentiviral production (13); it was used here to facilitate subsequent viral production experiments. To create the continuously expressing 293ET-Spl cells, the human embryonic kidney cell line 293ET (expressing EBNA-1 plus SV-40 large T antigen) was used to support episomal replication of the pCEP plasmid. Cells were transfected with pCEP/Spl using lipofectamine 2000 according to the manufacturer's instructions, and $48 \mathrm{~h}$ post transfection $1 \mu \mathrm{g} / \mathrm{ml}$ puromycin was added to select plasmid-containing cells. After 3 weeks selection, the cells showed good growth in $1 \mu \mathrm{g} / \mathrm{ml}$ puromycin, secreted Spätzle stably and continuously (data not shown), and were used for protein production experiments. H6-18 was routinely maintained in DMEM with 10\% FCS and 293ET-Spl was maintained in DMEM with 10\% FCS plus $1 \mu \mathrm{g} / \mathrm{ml}$ puromycin.

Synthesis of cryogel substrate materials 
Polyacrylamide cryogel substrate was synthesized from a $6 \% \mathrm{w} / \mathrm{v}$ aqueous mixture of acrylamide and methylene bisacrylamide at a ratio of 1:2.3. The reaction mixture was chilled in an ice bath for 45 mins. The reaction mixture was magnetically stirred, deoxygenated, and kept under nitrogen atmosphere at all times. $49 \mu \mathrm{l}$ of the catalyst TEMED was added to the reaction mixture 2 min prior to initiating the reaction with $0.03 \mathrm{~g}$ ammonium persulfate. Approximately 1 minute after the initiation of polymerization the reaction mixture was poured into $10 \mathrm{ml}$ syringe moulds that were chilled to $-20^{\circ} \mathrm{C}$ within a cryostat (CP instrument, Saffron Walden, UK) and sealed. The polymerisation reaction was allowed to proceed at $-20^{\circ} \mathrm{C}$ for approximately 24 hours. The outer diameter and height of the resulting cryogel monolith was $14 \mathrm{~mm}$ and $63 \mathrm{~mm}$ respectively.

\section{Perfusion culture of mammalian tissue cells on the cryogel substrate}

Cryogel substrates were housed within $10 \mathrm{ml}$ syringe barrels (Becton Dickenson, ON, CAN) which were modified with an inlet port. Sterilisation was carried out by autoclave. Prior to the seeding process the substrates were washed with $50 \mathrm{ml}$ of PBS, equilibrated with $50 \mathrm{ml}$ culture medium and then warmed to $37^{\circ} \mathrm{C}$.

To create the inoculum approximately $4.00 \times 10^{7}$ cells were grown in an incubator at $37^{\circ} \mathrm{C}$ in $\mathrm{T}-175$ flasks using DMEM medium supplemented with $10 \%$ FCS and $1 \%$ penicillin and streptomycin. Cells were trypsinised and then suspended in $4 \mathrm{ml}$ of culture medium. The inoculum was dispersed within the cryogel substrate by injection. The inlet and outlet to the substrate housing were each connected to separate $20 \mathrm{ml}$ syringes using sterile silicone tubes. The cell slurry was pumped into the gel using the two $20 \mathrm{ml}$ syringes. Whilst one syringe plunger was being slowly depressed $4 \mathrm{ml}$ of effluent from the substrate was collected in the other syringe. Afterwards the seeded gel was incubated at $37^{\circ} \mathrm{C}$ for 10 hours without perfusion. Perfusion was commenced and the first $15 \mathrm{ml}$ of effluent from the seeded scaffold was collected. The effluent was pooled with any residual culture medium contained in the syringes that were used for seeding. The number of viable cells within the pooled fraction was quantified using the trypan blue stain and a haemocytometer. 5 cell counts were carried out and an average number of cells calculated. Viability of cells was determined by dividing the viable cell count by the total cell count.

A stirred tank bioreactor (Applikon Biotechnology, RTM, NL) was refitted with inlet and outlet lines to allow continuous recirculation of culture medium through the cryogel substrate (Fig. 1). $550 \mathrm{ml}$ of DMEM culture medium was supplemented with $10 \%$ FCS, penicillin/streptomycin, and $0.2 \%$ antifoam. The $\mathrm{pH}$ was measured continuously in the culture medium reservoir tank. To achieve aeration a gas mixture composed of $95 \%$ air and $5 \% \mathrm{CO}_{2}$ was continuously sparged into the culture medium reservoir at a rate of $60 \mathrm{ml} / \mathrm{min}$. The culture medium was mixed with a single Rushton turbine impeller at a rate of $205 \mathrm{rpm}$. To ensure sterility, the bioreactor, ancillary tubing, and fittings were autoclaved. All gases entering or leaving the stirred tank were sterile filtered. Culture medium was replaced when nutrients were exhausted and high lactate concentrations as indicated by $\mathrm{pH}$. A peristaltic pump (Watson Marlow, Wilmington, USA) was used to draw medium at a flowrate of 1 $\mathrm{mL} / \mathrm{min}$ from the stirred tank reservoir and pump it through the cryogel substrate, which was incubated at $37^{\circ} \mathrm{C}$ in a water bath, and back into the reservoir. $1 \mathrm{ml}$ culture fractions were taken each day from inline sampling assemblies situated before the inlet to the column and after the outlet (Figure 1). The sample was examined under microscope for the presence of bacterial or yeast contaminations. Each sample was then stored at $-80^{\circ} \mathrm{C}$. 
On-column gene transfection was carried out by exposing cells to a recirculating transfection mixture composed of $120 \mu \mathrm{g}$ of pcDNA3.1/Spl or pHRVSINctwSVGFP and $300 \mu \mathrm{l}$ of lipofectamine 2000 in $8 \mathrm{ml}$ of optiMEM medium according to manufacturer's instructions. The transfection mixture was recirculated through an isolated 'transfection loop' using a second peristaltic pump which allowed perfusion of the cell supports without dilution (Fig. 1). The duration of the recirculation was 2 hours in transfection experiment 1 and 4 hours in transfection experiment 2. Afterwards in both cases the flow of medium was diverted to the main culture medium reservoir and perfusion was resumed with bulk media. The duration of the first 'on-column' gene transfection experiment of the monolith culture (OC-T1) was 14 days and transfection experiment 2 (OC-T2) was 10 days. Transfection procedure was carried out on day 5 of both cultures. Continuous expression of Spätzle by 293ET/Spl cells using the monolith bioreactor was carried out for 18 days. This experiment is denoted in the text as OC-CExp. In all experiments involving the continuously expressing cell line, puromycin $(1 \mu \mathrm{g} / \mathrm{ml})$ was added to the culture medium to achieve continuous expression of the transgene.

The D glucose and $\mathrm{L}(+)$ lactate concentrations were measured using Biovision assay kits (CA, USA). The total number of cells present in the $10 \mathrm{ml}$ cryogel substrates after running the bioreactor was estimated based on the average content of DNA present in three sections of gel of approximately $3 \mathrm{ml}$ in volume as follows. Three $3 \mathrm{ml}$ sections of cryogel substrates were cut using a surgical blade. The first cylindrical section was cut from a region of the cryogel which was close to the housing inlet, the second section was taken from a region approximately at the centre of the scaffold, and the final section was taken from the far end of the monolith which was close to the housing outlet. The sections were frozen in liquid nitrogen and ground into a paste using a mortar and pestle. $500 \mu \mathrm{l}$ of a buffer consisting of $10 \mathrm{mM}$ Tris- $\mathrm{HCl}, 10 \mathrm{mM} \mathrm{KCl,} 2 \mathrm{mM}$ EDTA, $4 \mathrm{mM} \mathrm{MgCl}$, and 2.5\% Triton X$100, \mathrm{pH} 7.6$ was added to each sample and mixed. $1 \mathrm{ml}$ of a solution consisting of $50 \mathrm{mM}$ Tris-Cl, $100 \mathrm{mM}$ EDTA, $0.1 \%$ SDS, and $200 \mu \mathrm{g}$ proteinase K (Sigma, UK), pH 8 was then added to each sample. The mixture was then incubated at $50^{\circ} \mathrm{C}$ for 6 hours. A phenol chloroform technique was used to extract DNA from the mixture after the enzymatic digestion of the cells and DNA was precipitated in ethanol (14). DNA pellets were resuspended in tris-EDTA buffer and the quantity of DNA was measured using the Quant-iT dsDNA assay kit (Molecular probes inc. OR, USA).

Using T-flasks several cell numbers up to $1.00 \times 10^{8}$ cells were prepared and the DNA from them was extracted and quantified. A working curve of cell number vs. DNA content was created $(\mathrm{y}=$ $\left.1.47 \times 10^{-6} \mathrm{x}+11.1, \mathrm{R}^{2}=0.93\right)$. Using this working curve the total cell number in the cryogel substrate could be estimated.

\section{Batch culture of mammalian tissue cells on TCPS.}

Experiments involving growth of cells on TCPS were carried out by seeding $1 \times 10^{5}$ cells in 6 well plates (Nunc, NY, USA) containing $4 \mathrm{ml}$ DMEM culture medium supplemented with 10\% FCS, with $1 \%$ penicillin and streptomycin, and growing cultures for up to 6 days using standard techniques. Samples of supernatant were removed from each well and assayed daily for Spätzle, glucose and lactate levels. Cell numbers were quantified using a haemocytometer. Cultures of 293ET/spl grown on TCPS are denoted TCPS-CExp.

Transient transfection was carried out at day 3 using a 'high' and 'low' concentration of DNA, which corresponded to $20 \mu \mathrm{g}$ and $4 \mu \mathrm{g}$ in $250 \mu \mathrm{l}$ of opti-MEM medium respectively. $10 \mu \mathrm{l}$ of 
lipofectamine 2000 in $250 \mu \mathrm{l}$ opti-MEM was mixed with the DNA solution to create a transfection mixture which was added to the culture to bring the final volume to $4 \mathrm{ml}$. These experiments are denoted TCPS-T 'high' and TCPS-T 'low' respectively. Samples of culture supernatant were taken every 24 hours for 3 days after transfection for analysis.

Continuous Spätzle production was also assessed using T-175 flasks. 3 cultures were seeded with $5.00 \times 10^{6} 293 \mathrm{ET} / \mathrm{Spl}$ cells and grown to confluency in $30 \mathrm{ml}$ of culture medium over 3 days. The supernatant was harvested and Spätzle content was determined by ELISA.

\section{Laser scanning confocal microscopy and scanning electron microscopy.}

To prepare samples the $10 \mathrm{ml}$ cryogel column was sectioned along its length into 5 discs of approximately $2 \mathrm{ml}$ in volume using a scalpel. Thin radial sections were cut from each of the 5 discs and mounted onto glass microscope slides. These samples were immediately examined with a fluorescence microscope (Leica, IL, USA). An excitation wavelength of $495 \mathrm{~nm}$ and an emission wavelength $518 \mathrm{~nm}$ was used. The image shown in Figure 7 was taken from a scaffold section located approximately $10 \mathrm{~mm}$ from the inlet of the column housing.

To prepare samples for environmental scanning electron microscope (ESEM) analysis, cryogel scaffolds from experiment OC-T1 were sectioned, fixed, washed thoroughly with PBS, and then refrigerated and stored in the dark until examination. The samples were transferred to the FEI XL30 SEG scanning electron microscope (Philips, EIN, NL) stage for examination, a relative humidity of $60 \%$ was achieved at pressure of $10-15$ Torr.

For cryoscanning electron microscope analysis cryogel samples were hydrated in an aqueous mixture containing 5\% v/v ethanol and then plunged into liquid nitrogen. The samples were subsequently transferred under vacuum to a cryo-preparation stage and fractured under vacuum with a scalpel. The sample was then transferred to the FEI XL30 SEG scanning electron microscope (Philips, EIN, NL) cryostage for examination.

\section{Determination of Spätzle binding activity by ELISA}

CoStar 3590 Elisa (EIA/RIA) plates were coated overnight with purified anti-FLAG clone M2 antibody in PBS. The plates were blocked for $2 \mathrm{~h}$ with $2 \%$ FCS in PBS then washed thoroughly with PBS containing $0.05 \%$ tween 20. Sample was applied and the plates incubated overnight, then washed thoroughly and probed with HRP-conjugated anti-His tag antibody. After 4 hours, the plates were washed and developed with o-phenylenediamine dihydrochloride substrate. Concentrations were determined by comparison with a standard curve prepared using known concentrations of Spätzle that had been expressed in insect cells using baculovirus and purified by immobilised metal affinity chromatography and size exclusion chromatography (15).

\section{Measurement of Spätzle functional activity}

An insect S2 cell line containing a drosomycin-luciferase reporter was used to measure Spätzle activity (12). Spätzle is inactive until the pro-domain is cleaved; in this study we utilised engineered Spätzle containing a TEV protease site inserted between the pro-domain and the active C106 cytokine domain, and activated it using recombinant AcTEV protease. For activity determination, samples were processed from supernatant taken from experiment OC-CExp. Approximately $500 \mathrm{ml}$ of conditioned medium was harvested from the culture at day $10.20 \mathrm{mM}$ imidazole was added to the 
supernatant, which was then passed by gravity flow through a column containing $1 \mathrm{ml}$ Nickel-NTA agarose (Qiagen), followed by washing, elution in $250 \mathrm{mM}$ imidazole and buffer exchange into PBS using a $10 \mathrm{kDa}$ MWCO centrifugal concentrator (Qiagen). Protein concentration was determined by UV absorption at $260 \mathrm{~nm}$ and Bradford protein assay, and a total of $200 \mu \mathrm{g}$ protein was recovered in $1 \mathrm{ml}$. Replicate portions were tested either uncleaved or cleaved with AcTEV and samples were added at a concentration of $20 \mathrm{nM}$ to S2-drosomycin-luciferase reporter cells (12). Bioreactorproduced protein was compared to positive control samples of cleaved Spätzle produced by transient transfection of 293 cells in TCPS. After overnight stimulation, cells were lysed and lucifease determined using a luciferase assay system (Promega). Data shown are fold induction of luciferase over unstimulated cells.

\section{Results}

The production of two model proteins in perfused monolith culture was studied. The first protein, a tagged version of the Drosophila cytokine Spätzle, was chosen since it is secreted in an inactive form but can easily be cleaved to measure activity, and therefore confirm correct folding $(12,15)$. Three bioreactions were carried out. Initially, 293ET/Spl cells continuously secreting Spätzle were grown to monitor continuous protein secretion; subsequently the lentiviral production 293 HEK line H1618 was used for transient transfection on the monolith bioreactor to monitor transient protein secretion. The second model protein, GFP, was used to investigate the spatial distribution of transiently expressing H16-18 cells within the monolith scaffold after on-column transfection.

\section{Characterisation of monolithic scaffold and seeding}

The cryogel scaffold material possesses a complex structure in which large sheets of polymer create the pore walls (Figure 2A). High power magnification shows that the polymer sheets are microporous giving the monolith a high surface area (Figure 2B). Whilst there exists a local degree of disorder, these gels have a characteristic overall structure that is reproducible from batch to batch .

$40 \times 10^{6}$ cells were seeded in the scaffold and after seeding the number of cells remaining in the seed medium was counted to determine seeding efficency. With the continuously expressing cell line on the monolith, $94 \pm 0.1 \%$ remained within the scaffold after the seeding process (OC-CExp) and $95 \pm$ $2 \%$ and $98 \pm 0.2 \%$ of cells were retained after seeding in transient transfection on monolith bioreactions 1 and 2 (OC-T1 and OC-T2). The viability of cells within the fraction taken immediately after starting perfusion was also high at $95 \%, 94 \%$, and $91 \%$ respectively.

ESEM allows visualisation of the structure of the cryogel polymer in its native hydrated state. Widespread growth of cells occurred in the monolith after perfusion culture (Figure 3).

\section{Determination of endpoint cell numbers by DNA mass}

Total genomic DNA content was measured because trypsinisation and quantification by haemocytometry gave highly variable results. It is important to note that the DNA assay method can potentially over-estimate cell numbers due to the inclusion of residual genomic DNA from dead cells. The data in Table 1 shows a strong positive correlation between time in culture and the total amount of DNA recovered from the scaffolds, confirming active cell growth occurred on the monoliths. Using a standard curve of cells versus DNA content the content of DNA associated with the inoculum was approximately $55 \mu \mathrm{g}$ DNA. Therefore, after 18 days of culture in the bioreactor an 
841-fold increase in DNA occurred in the OC-CExp cell culture. A 25 and 13-fold increase in DNA content was observed in OC-T1 and OC-T2 after 14 and 10 days culture respectively.

\section{Kinetics of continuously expressing cultures: Spätzle output, $\mathrm{pH}$, glucose and lactate analysis}

Continuous Spätzle expression from 293ET/Spl cells was compared in the perfused bioreactor system, in 6 well TCPS plates (Figure 4) and in T-175 flasks. To accurately quantify protein production a sandwich ELISA was used that captured Spätzle via the FLAG tag and detected it via the his-tag. Concentrations in culture medium samples were compared with a highly purified sample of Spätzle of known concentration made independently in a baculovirus system (15) and confirmed to be $>90 \%$ pure by polyacrylamide gel electrophoresis (data not shown). The illustrated growth profile of immortalised mammalian cells on TCPS is typical, where newly plated cells display a lag period followed by near exponential growth before confluency causes the proliferation rate to decrease and the total cell numbers to decline over time (16). The kinetics of metabolite production and nutrient consumption also show a typical profile with glucose conversion into lactate at close to a 1:1 mol ratio. The rate of glucose consumption during culture on the monolith is initially similar to TCPS but a gradual increase in rate was registered over the course of the experiment. Thus the uptake of nutrients from the cutlure medium by the cell culture gradually increased over time. Assaying Spätzle concentration in the culture medium revealed that recombinant protein production correlated positively with cellular proliferation. The greatest increase in Spätzle production occurred during the near exponential phase of cell growth. For contextual purposes it is important to note that using aT-175 flask, an average of $14.58 \pm 0.52 \mu \mathrm{g}$ of Spätzle was produced in 4 days of culture. Therefore approximately 83 of these units would be required to obtain the mass of Spätzle produced in the perfused reactor over 18 days. If the average amount of Spätzle produced per cell per 24 hours in the TCPS-CExp experiment is considered, then based on the mass of Spätzle produced in the final $24 \mathrm{hrs}$ of perfusion culture in the monolith, the equivalent number of cells present is estimated at $5.31 \times 10^{9}$. This value supports the high estimate of total cell numbers obtained from the DNA assays (Table 2).

To confirm that the protein detected in the ELISA was full-length and functionally folded, two further analyses were conducted. Firstly, PAGE and western blotting was performed and a FLAG reactive protein of the expected molecular weight was seen (data not shown). Secondly, we measured activity of the protein. The full-length Spätzle protein is not active until proteolytically cleaved; following cleavage of the engineered TEV protease site by recombinant AcTEV, the activated cytokine stimulates the S2 drosomycin-luciferase cell line via the Toll receptor (12). We purified Spätzle from a portion of the culture medium taken from OC-CExp, and found that after AcTEV cleavage it gave 44-fold induction of luciferase, whereas the uncleaved sample gave no induction (Figure 5). Therefore the protein produced has the expected activity, confirming correct folding.

\section{Kinetics of transiently transfected cultures: Spätzle production, $p H$ and metabolite analysis}

In some instances, transient transfection is preferable to establishing stably transfected cell lines. Two experiments were carried out to examine if transfection of cells within monolith perfusion culture was possible for transient expression of recombinant protein. In both cases, secretion of Spätzle was detected by ELISA within 48 hrs after transfection on the monolith, (Figure 6). Incubating cells with transfection reagent for $4 \mathrm{hrs}$ (OC-T2) resulted in a doubling in overall productivity of Spätzle as compared with the $2 \mathrm{hr}$ contact period (OC-T1). Transient expression 
experiments were also conducted with TCPS cell cultures which provided a benchmark useful in judging bioreactor performance (Table 3). Comparing the results of the continuously expressing cell cultures with the data obtained in OC-T1, OC-T2, TCPS-T 'low' and TCPS-T 'high', it is clear that the amount of Spätzle produced by transient transfection was substantially less than the amount obtained from continuously producing cells. In terms of productivity $4.12 \mathrm{fg} \mathrm{Spätzle} \mathrm{cell}^{-1}$ was obtained in TCPS -T 'low' experiment as compared with $14.30 \mathrm{fg}$ Spätzle per cell in the OC-T2 experiment. Given that the concentration of transfection complexes applied in both of those experiments was the same it is suggested that the monolith bioreactor performed advantageously, and can be considered a compact and efficient system for transient transfection operations. The cell specific productivity from the on-column transfection experiments is likely to be an underestimate given that the cell numbers used in the calculation were not live cell numbers but instead total cell numbers calculated from the DNA content in the scaffolds.

For comparison, the surface area of the TCPS culture was $10 \mathrm{~cm}^{2}$ whereas that of a solid cylinder of the same dimensions as the monolith is approximately $31 \mathrm{~cm}^{2}$, yet the reactor produced 571 -fold more protein. In part due to the large culture volume used in the bioreaction, the overall concentration of Spätzle obtained was too low for purification and confirmation of activity; however, the protein detected by ELISA was seen to be the correct size by western blot (data not shown).

\section{Scanning laser confocal microscopy after GFP transfection}

To investigate the distribution of transfected cells within the monolith, a separate experiment was conducted in which GFP was used to identify transgene expression. LSCM allows the cryogel material to be microscopically visualised in its native hydrated state. A fluorescent signal which indicated GFP expression was found in cells distributed throughout the length and width of the scaffold section (figure 7). Lesser fluorescence was detected in sections that were taken towards the outlet of the scaffold housing.

\section{Discussion}

We demonstrate here for the first time that it is possible not only to grow cells to very high densities in perfused monolith bioreactors, but that it is simple to transfect cells grown in this way. Polyacrylamide cryogel monoliths are advantageous cell substrates because of the high voidage, broad range of pore sizes $(<100 \mu \mathrm{m})$, and surface features they possess. At the micron scale the polymeric structure is complex (Figure 2). Sheets of polymer arrange in a lamellar pattern and are separated by large voids which function as pores where flowthrough occurs in the material. Thin polymer strands are attached to the surface of the large polymer sheets. These attributes give the material a high accessible surface area which is a prerequisite for high density cell growth. ESEM images (Figure 3) show that in the hydrated state the thin polymer strands attached to the polymer sheets are no longer visible. Also, the polymer surfaces appear more rounded with a smoother texture after hydration. Polyacrylamide is hydrophilic and water associated with the material could have altered the local conformation of the substrate. The large macropores remain present in the hydrated material. These properties allow cell seeding to be carried out rapidly and effectively without undue loss of cell viablity.

The 3-D environment of a culture substrate plays an important role in supporting the growth and function of mammalian cells (17). During cell culture on the monoliths a pattern of cell growth emerged. In the determination of cell number by DNA extraction experiments, the largest fraction 
was measured predominantly in the region of the scaffold that was closest to the housing inlet (Table 1). This result was expected given that during operation the highest concentration of nutrients occurs there and the concentration of waste products is lowest. By extension, cells located in the middle or near the outlet of the monolith were probably exposed to a harsher culture environment and as a result less cell growth was anticipated. Nevertheless, the possibility also exists that the observed cell distributions resulted from the seeding method, which may have led to gradual deposition of progenitor cells across the length of the scaffold. Regardless of the gross patterns of colonisation, the scaffolds proved capable of supporting large cell populations. In terms of cell doublings, the observed cell densities represent $\geq 4, \geq 5$, and $\geq 10$ doublings after 10,14 and 18 days for the OCT2, OC-T1, and OC-CExp cell cultures respectively (assuming no cell death), which suggests a consistent rate of cell division during culture on the monoliths (i.e. 1 population doubling every 2 days). Other possible reasons for the difference in cell numbers are the toxic and cytostatic effects of the transfection agent, differences between cell types, and the greater number of medium changes that was done for the continuously expressing cell culture (18). By way of comparison, a cell culture which utilises $10 \mathrm{ml}$ (swollen volume) of microcarriers (e.g. Cytodex, GE healthcare) possessing a surface area of $8800 \mathrm{~cm}^{2}$ would be capable of supporting approximately $1 \times 10^{9}$ cells, which is 35 fold lower than the estimated $3.5 \times 10^{10}$ cells grown on the monolith substrate.

Comparison of the cell specific productivity between the OC-Cexp and the TCPS-Cexp experiments reveal the clear advantages of continuous perfusion operation over batch culture. Recombinant protein production is maximised during phases of rapid cellular proliferation which is achieved by providing fresh culture medium and enough extra space for uninhibited expansion of the colony. Productivity limitation in the TCPS cultures arises from the frequent, time consuming requirement to re-culture cells as they quickly reach confluence and considerably reduce their rate of product output. The large surface area available for colonisation on the monolith in combination with the constant renewal of the culture medium after nutrient depletion is a major processing benefit. Cell growth on the cryogel scaffold was sustained and profuse throughout the entire culture, as evidenced by falls in $\mathrm{pH}$ levels in the medium as well as large amounts of Spätzle and lactate being produced and secreted by the cells (Figure 4). The process demonstrated a high overall productivity. The Spätzle protein was correctly folded and active (Figure 6). Due to low residence time of the product at $37^{\circ} \mathrm{C}$, the system is especially suitable for manufacture of unstable biological products.

Increasing the DNA concentration that cells are exposed to is one of the most powerful ways of improving transfection efficiency (4). By isolating the transfection complexes to the 'transfection loop' circuit in the bioreactor we were able to keep the volume of the transfection reaction mixture low and thus achieve a 70-fold higher concentration of DNA than would have been otherwise possible. The amount of time the transfection complexes were incubated with the cells in the monolith also proved to be a major determinant of culture productivity. Extending the time period allowed greater contact of transfection complexes with the cells and resulted in higher levels of gene expression (Figure 5). Longer recycling of the transfection mixture is expected to improve culture productivity further. In comparison with the conventional cell culture method, the monolith cell culture was capable of expressing up to 3.5 times more Spätzle per cell by the transient transfection technique. This result is in agreement with published literature which reports that transfection of cells in a 3-D environment promoted a higher gene expression level and longer expression time as compared to 2-D transfection $(7,19)$. The LSCM study of the distribution of GFP transfected cells (Figure 7) shows that access of transfection complexes to the interior of the scaffold where cells grow does not appear to be limited: fluorescent cells appeared throughout the monolith after 
sectioning. However the density of fluorescent cells observed within each section of the monolith gradually declined over the length of the monolith towards the outlet of the scaffold housing. This result supported the DNA analysis and was expected given that the greatest cell density occurred near the scaffold inlet and cell numbers gradually declined over the length of the monolith also. Therefore an increased likelihood of contact between cells and transfection reagent probably occurred at the scaffold inlet. Another possibility is that as the transfection complexes pass through the column they may become depleted due to absorption by cells. This suggests that monoliths with shorter aspect ratios could be used to achieve better transfection; which might also facilitate cell seeding. Also such column dimensions may minimise exposure of cells to metabolic waste products during culture and thereby promote more even coverage of the scaffold with cells.

\section{Conclusions}

The flexibility and benefits of transient transfection technology in the manufacturing of biological products are clear. In the past, an improved productivity has resulted from the use of novel transfection promoting chemicals and equipment, more receptive cell lines, optimised concentrations of transfection complexes, and formulated culture medium free from inhibitory substances. This paper demonstrates the utility of porous monolithic substrates for the manufacture of recombinant proteins by mammalian cells in perfusion culture. Data was presented that compared the performance of a stable and transient gene expression strategy on the monolith with cells cultured on standard tissue culture polystyrene using conventional methodologies. The structure of the monolith and the distribution of cells within it were analysed in detail by cryo-scanning electron microscopy, environmental scanning electron microscopy, and laser scanning confocal microscopy. Glucose, lactate and the gene product Spätzle were specifically assayed, kinetic profiles were established, and comparisons were drawn. Cell numbers were evaluated based on recombinant protein output, total DNA content in the scaffolds, and based upon metabolic markers present in the culture medium. Cell seeding methods were assessed and shown to be highly effective. We expect the processes demonstrated herein to be useful for the production of sensitive protein products and especially viral vectors which are difficult to manufacture due to their toxic affect upon host cells and their sensitive environmental requirements. Perfused monolithic cell cultures represent a new, powerful and flexible manufacturing platform for the production of recombinant proteins and other high value biopharmaceuticals.

\section{Acknowledgements}

The authors thank Jeremy Skepper for assistance with the cryo-scanning electron microscopy images (Multi-imaging centre, University of Cambridge, UK), Trevor Fairhead for assistance with environmental scanning electron microscopy work (Cavendish Laboratory, University of Cambridge, UK), Linda Lloyd and Rod Hobbs for advice and financial support (Varian, Shropshire, UK) and the UK Engineering and Physical Sciences research council for funding a CASE studentship (for M.C.C) during the tenure of which this work was carried out. 
Tables:

Table 1 Cell density in bioreactor monolith determined by DNA content.

\begin{tabular}{llll}
$\begin{array}{l}\text { Experiment } \\
\begin{array}{l}\text { Duration of culture } \\
\text { (hrs) }\end{array}\end{array}$ & $\begin{array}{l}\text { OC-T1 } \\
\text { Total DNA }\end{array}$ & $\begin{array}{l}\text { OC-T2 } \\
240\end{array}$ & $\begin{array}{l}\text { OC-CExp } \\
432\end{array}$ \\
$\begin{array}{l}\text { recovered }(\mu \mathrm{g}) \\
\begin{array}{l}\text { Estimated total } \\
\text { number of cells }\end{array}\end{array}$ & 1390 & 690 & 46300 \\
$\begin{array}{l}\text { Section 1 } \\
\text { (Cells/ml scaffold) }\end{array}$ & $1.46 \times 10^{8} \pm 1.36 \times 10^{7}$ & $8.41 \times 10^{7} \pm 8.54 \times 10^{6}$ & $3.69 \times 10^{9} \pm 1.64 \times 10^{8}$ \\
$\begin{array}{l}\text { Section 2 } \\
\text { (Cells/ml scaffold) }\end{array}$ & $1.15 \times 10^{8} \pm 1.40 \times 10^{7}$ & $4.12 \times 10^{7} \pm 4.21 \times 10^{6}$ & $4.88 \times 10^{9} \pm 3.20 \times 10^{8}$ \\
$\begin{array}{l}\text { Section 3 } \\
\text { (Cells } / \mathrm{ml} \mathrm{scaffold)}\end{array}$ & $4.80 \times 10^{7} \pm 4.13 \times 10^{6}$ & $2.39 \times 10^{7} \pm 2.27 \times 10^{6}$ & $1.94 \times 10^{9} \pm 2.14 \times 10^{8}$ \\
\hline
\end{tabular}

${ }^{\text {a }}$ Total genomic DNA was extracted from sections cut from the monolith at the end of cell culture, and DNA quantity was compared with that obtained from known cell numbers.

Table 2. Comparison of cell growth and Spätzle production from 293ET/Spl cells in a monolithic bioreactor or conventional TCPS.

\begin{tabular}{lll} 
Experiment & TCPS-CExp & OC-CExp \\
\hline Gene Expression mode & Continuous & Continuous \\
Total culture volume $(\mathrm{ml})$ & 4 & 2200 \\
Culture material & Tissue culture polystyrene & Polyacrylamide cryogel \\
Duration of culture $(\mathrm{hrs})$ & 144 & 432 \\
Spätzle produced $(\mu \mathrm{g})$ & 0.05 & 121 \\
Culture area $\left(\mathrm{cm}^{2}\right)$ & 10 & not measured \\
Estimated total number of & $10.1 \times 10^{6}$ & $3.83 \times 10^{10}$ \\
cells at end point of culture & &
\end{tabular}

Table 3. Comparison of Spätzle production after of H6-18 cells transiently transfected with pcDNA3.1/Spl in a monolithic bioreactor or in conventional TCPS.

\begin{tabular}{|c|c|c|c|c|}
\hline Experiment & $\begin{array}{l}\text { TCPS -T } \\
\text { 'low'a }\end{array}$ & $\begin{array}{l}\text { TCPS-T } \\
\text { 'high' }\end{array}$ & OC-T1 ${ }^{b}$ & $\mathrm{OC}-\mathrm{T} 2^{\mathrm{c}}$ \\
\hline Gene Expression mode & Transient & Transient & Transient & Transient \\
\hline Total culture volume $(\mathrm{ml})$ & 4 & 4 & 1100 & 550 \\
\hline Culture material & $\begin{array}{l}\text { Tissue culture } \\
\text { polystyrene }\end{array}$ & $\begin{array}{l}\text { Tissue culture } \\
\text { polystyrene }\end{array}$ & $\begin{array}{l}\text { Polyacrylamide } \\
\text { cryogel }\end{array}$ & $\begin{array}{l}\text { Polyacrylamide } \\
\text { cryogel }\end{array}$ \\
\hline Duration of culture (hrs) & 120 & 120 & 336 & 240 \\
\hline Spätzle produced $(\mu \mathrm{g})$ & 0.02 & 0.07 & 3.87 & 7.39 \\
\hline $\begin{array}{l}\text { Estimated total number of } \\
\text { cells }\end{array}$ & $3.14 \times 10^{6}$ & $3.14 \times 10^{6}$ & $1.05 \times 10^{9}$ & $5.15 \times 10^{8}$ \\
\hline
\end{tabular}

Experiments ${ }^{\mathrm{a}, \mathrm{b} \text {, and c }}$ were conducted with the same concentration of transfection complexes. In experiment ${ }^{b}$ the transfection mixture was recriculated in the transfection loop for 2 hours, and in experiment ${ }^{c}$ the transfection mixture was recirculated for 4 hours. 


\section{Figure Legends}

Figure. 1. Schematic illustrating bioreactor setup.

Figure 2. Cryo-scanning electron microscopy of the polyacrylamide scaffold.

Figure has A and B sections which should be explained.

Figure 3. Environmental scanning electron microcopy of scaffold before (A) and after (B) perfusion culture. A layer of cells has effectively colonized a polymer sheet which provided a favourable location where cells anchored and proliferated.

Figure 4. Growth, Spätzle production and metabolic activity of 293ET/Spl cells grown on a monolithic bioreactor or TCPS. (A) Plot showing the number of cells v/s time during culture for 6 days in the TCPS-CExp experiment. (B) Plot showing the mass of Spätzle protein in the culture medium v/s time by the TCPS-CExp culture experiment, (C) plot showing ( $\mathbf{a})$ glucose and $(\downarrow)$ lactate levels in the media during culture on TCPS-CExp. (D) $\mathrm{pH}$ profiles of culture medium during perfused cell culture in monolith experiment OC-CExp. (E) Graph showing the mass of Spätzle protein in the culture medium during perfused cell culture in monolith experiment OC-CExp. (F) plot showing ( $\mathbf{a})$ glucose and $(\diamond)$ lactate levels in the culture medium during perfused cell culture on in monolith experiment OC-CExp.

Figure 5. Spätzle produced in perfusion culture is active when cleaved. Spätzle was purified from OC-CExp culture medium by metal affinity chromatography, and tested uncleaved or cleaved with AcTEV protease. 20nM samples were added to S2-drosomycin-luciferase reporter cells and incubated overnight, followed by lysis and determination of luciferase activity, expressed as fold increase over buffer control.

Figure 6. Growth and Spätzle production after transient transfection of H6-18 cells grown on a monolithic bioreactor with pcDNA3.1/Spl. (A) Graph showing the $\mathrm{pH}$ profile over the course of the culture in experiment OC-T1 (2h transfection period). (B) Plot showing the production of Spätzle protein v/s time in experiment OC-T1. (C) (घ) Glucose and ( $\downarrow$ ) lactate levels in the media during OC-T1.(D) $\mathrm{pH}$ profiles during cell culture in experiment OC-T2. (E) Graphs the concentration of Spätzle protein over the course of the culture in OC-T2. (F) (घ) Glucose and ( $\bullet$ lactate levels in the media during cell culture during OC-T2. The arrows indicate when the transfection procedure was initiated during the culture.

Figure 7. GPF expression within the scaffold after transient transfection of cells grown in monolithic bioreactor. Figure (A) is a photograph of the cryogel scaffold within its housing which was removed from the bioreactor after culture. Vertical lines indicate where sections were cut from the scaffold. The images marked (B.) and (C.) are laser scanning confocal microscope images of a latitudinal section of the cryogel monolith (i.e. section 2) taken after H6-18 cells were transfected with a plasmid carrying the GFP gene during perfused culture.

\section{References:}

1. Burns JC, Friedmann T, Driever W, et al. (1993) Vesicular stomatitis virus G glycoprotein pseudotyped retroviral vectors: concentration to very high titer and efficient gene transfer into mammalian and nonmammalian cells. Proc Natl Acad Sci U S A. 90:8033-7.

2. Segura MM, Garnier A, Durocher Y, et al. (2007) Production of lentiviral vectors by largescale transient transfection of suspension cultures and affinity chromatography purification. Biotechnol Bioeng. 98:789-99. 
3. Wurm FM (2004) Production of recombinant protein therapeutics in cultivated mammalian cells. Nat Biotechnol. 22:1393-8.

4. Luo D, Saltzman WM (2000) Enhancement of transfection by physical concentration of DNA at the cell surface. Nat Biotechnol. 18:893-5.

5. Kong D, Cardak S, Chen M, et al. (1999) High cell density and productivity culture of Chinese hamster ovary cells in a fluidized bed bioreactor. Cytotechnology. 29:215-20.

6. Kong D, Chen M, Gentz R, Zhang J (1999) Cell growth and protein formation on various microcarriers. Cytotechnology. 29:149-56.

7. Knibbs RN, Dame M, Allen MR, et al. (2003) Sustained high-yield production of recombinant proteins in transiently transfected COS-7 cells grown on trimethylamine-coated (hillex) microcarrier beads. Biotechnol Prog. 19:9-13.

8. Thelwall PE, Neves AA, Brindle KM (2001) Measurement of bioreactor perfusion using dynamic contrast agent-enhanced magnetic resonance imaging. Biotechnol Bioeng. 75:682-90.

9. Svec F, Frechet JM (1996) New designs of macroporous polymers and supports: from separation to biocatalysis. Science. 273:205-11.

10. Kumar A, Bansal V, Nandakumar KS, et al. (2006) Integrated bioprocess for the production and isolation of urokinase from animal cell culture using supermacroporous cryogel matrices. Biotechnol Bioeng. 93:636-46.

11. Nilsang S, Nandakumar KS, Galaev IY, et al. (2007) Monoclonal antibody production using a new supermacroporous cryogel bioreactor. Biotechnol Prog. 23:932-9.

12. Weber AN, Tauszig-Delamasure S, Hoffmann JA, et al. (2003) Binding of the Drosophila cytokine Spatzle to Toll is direct and establishes signaling. Nat Immunol. 4:794-800.

13. Cheeks MC, Kamal N, Sorrell A, et al. (2008) Immobilized metal affinity chromatography of histidine-tagged lentiviral vectors using monolithic adsorbents. J Chromatogr A.

14. Hofstetter JR, Zhang A, Mayeda AR, et al. (1997) Genomic DNA from mice: a comparison of recovery methods and tissue sources. Biochem Mol Med. 62:197-202.

15. Gangloff M, Murali A, Xiong J, et al. (2008) Structural insight into the mechanism of activation of the Toll receptor by the dimeric ligand Spatzle. J Biol Chem. 283:14629-35.

16. Skehan P, Friedman SJ (1984) Non-exponential growth by mammalian cells in culture. Cell Tissue Kinet. 17:335-43.

17. Varani J, Dame M, Rediske J, et al. (1985) Substrate-dependent differences in growth and biological properties of fibroblasts and epithelial cells grown in microcarrier culture. J Biol Stand. 13:67-76.

18. Mercille S, Johnson M, Lanthier S, et al. (2000) Understanding factors that limit the productivity of suspension-based perfusion cultures operated at high medium renewal rates. Biotechnol Bioeng. 67:435-50.

19. Xie Y, Yang ST, Kniss DA (2001) Three-dimensional cell-scaffold constructs promote efficient gene transfection: implications for cell-based gene therapy. Tissue Eng. 7:585-98. 